\title{
Small RNA fragments in complex culture media cause alterations in protein profiles of three species of bacteria
}

\author{
Asalapuram R. Pavankumar, ${ }^{*}$, Sudalaiyadum Perumal Ayyappasamy*, and Krishnan Sankaran \\ Centre for Biotechnology, Anna University, Chennai, India
}

BioTechniques 52:167-172 (March 2012) doi 10.2144/000113819

Keywords: Luria Bertani broth; small RNA; RNA-depletion; subcellular proteins; protein expression

Supplementary material for this article is available at www.BioTechniques.com/article/113819

${ }^{*}$ A.R.P. and S.P.A. contributed equally to this work, ${ }^{\dagger}$ A.R.P. current address is School of Biotechnology, Royal Institute of Technology (KTH), Stockholm, Sweden.

Efforts to delineate the basis for variations in protein profiles of different membrane fractions from various bacterial pathogens led to the finding that even the same medium [e.g., Luria Bertani (LB) broth] purchased from different commercial sources generates remarkably dissimilar protein profiles despite similar growth characteristics. Given the pervasive roles small RNAs play in regulating gene expression, we inquired if these source-specific differences due to media arise from disparities in the presence of small RNAs. Indeed, LB media components from two different commercial suppliers contained varying, yet significant, amounts of 10-80 bp small RNAs. Removal of small RNA from LB using RNaseA during media preparation resulted in significant changes in bacterial protein expression profiles. Our studies underscore the fact that seemingly identical growth media can lead to dramatic alterations in protein expression patterns, highlighting the importance of utilizing media free of small RNA during bacteriological studies. Finally, these results raise the intriguing possibility that similar pools of small RNAs in the environment can influence bacterial adaptation.

During our analysis of subcellular protein composition in enteropathogenic Escherichia coli (EPEC), we frequently noted inconsistencies among protein profiles, even under seemingly identical growth conditions using Luria Bertani (LB) medium prepared from components purchased through either Himedia (HI-LB; Mumbai, Maharashtra, India) or Invitrogen (IN-LB; Carlsbad, CA, USA).

LB is a complex media consisting of tryptone, yeast extract, and $\mathrm{NaCl}$ used extensively in microbiology and cell biology studies of various processes, including host-microbe interactions (1). When we analyzed ethanolprecipitated fractions of autoclaved LB, nucleic acid species smaller than 100 bp were identified. During the production of tryptone and yeast extracts, although tissues from different biological sources are subjected to harsh treatment procedures to remove nucleic acids and other contaminants, it is difficult to achieve complete hydrolysis of all the nucleic acid fragments. Our observations correlate with those of Chen et al. (2) suggesting that the protein expression studies carried out with commercial growth media containing enzymatic digests of casein, such as LB, engendered variations in protein profiles, leading us to speculate that these nucleic acid populations identified in LB media could act in a similar fashion to many recently identified small RNAs (sRNA) regulators to alter protein expression profiles.

In recent years, various biological functions have been attributed to RNAs $(3-5)$,including roles in the regulation of gene expression, gene silencing, coordinating intricate stress responses (6-8), and apoptosis (9). In addition, roles in quorum sensing and bacterial cell-cell communications (10-13) are also evident based on studies from bacterial pathogens like Vibrio harveyi, Pseudomonas fluorescens (12), and Escherchia coli (14). Although the exact mechanisms remain unclear, such regulatory noncoding sRNAs $(15,16)$ are also involved in population density-dependent activities such as virulence factor regulation $(17,18)$ in bacterial species like Erwinia, Vibrio cholerae, V. harveyi, Salmonella entricea, and Pseudomonas aeruginosa (17). Although substantial numbers of sRNA species and their related pathways still await further study, many of these could potentially function as metabolic regulators (19).

We examined the presence of sRNAs in LB media components from two different commercial sources. Subsequently, we compared the protein profiles of $E$. coli $\mathrm{DH} 5 \alpha, \mathrm{BL} 21$ (DE3), and pathogens such as enteropathogenic E. coli (EPEC), Salmonella typhimurium, and Shigella flexneri grown in LB, RNA-depleted LB (RDLB), and RDLB supplemented with RNA isolated from LB (reconstituted LB). In all cases, we observed significant differences in protein profiles. Our results support the hypothesis that nonspecific or specific interference by sRNAs in autoclaved LB medium can contribute to changes in bacterial protein expression.

\section{Materials and methods}

Preparation of LB medium

In this study, we used yeast extract and tryptone purchased from Himedia (HI-LB) and Invitrogen (IN-LB). HI-LB was prepared by dissolving $10 \mathrm{~g}$ tryptone, 5 gyeast extract, and $10 \mathrm{~g} \mathrm{NaCl}$ in $1 \mathrm{~L}$ distilled water and adjusting the $\mathrm{pH}$ to 7.2 with $1 \mathrm{NNaOH}$ prior to autoclave. In the case of IN-LB, $25 \mathrm{~g} \mathrm{LB}$ powder (containing $10 \mathrm{~g}$ tryptone, 5 g yeast extract, and $10 \mathrm{~g} \mathrm{NaCl}$ ) were dissolved in $1 \mathrm{~L}$ distilled water and autoclaved after adjusting the $\mathrm{pH}$ to 7.2.

\section{Preparation of RNA-depleted}

LB medium

RNA-depleted LB medium (RDLB) was prepared from both media (HI-LB and 
IN-LB) by two methods: (i) LB medium was incubated with $0.5 \mu \mathrm{g} / \mathrm{mL}$ RNaseA (Genie, Bangalore, Karnataka, India) at $37^{\circ} \mathrm{C}$ for $1.5 \mathrm{~h}$ to digest the RNA in the medium and then autoclaved; or (ii) the $\mathrm{pH}$ of the LB medium was increased from 7.2 to 11.0 using $5 \mathrm{M} \mathrm{NaOH}$ (Sisco Research Laboratories, Mumbai, Maharashtra, India), and after $15 \mathrm{~min}$ at room temperature, the $\mathrm{pH}$ was decreased to 7.2 using $11 \mathrm{~N} \mathrm{HCl}$ (Sisco Research Laboratories). In both the cases, we did not notice the presence of nucleic acids when the ethanol-precipitated fractions were analyzed on agarose gels, as described below. Since the second method was not compatible with bacterial growth and protein expression studies, we adopted method (i) for all the experiments in this study.

Analysis of nucleic acid content and agarose gel electrophoresis

We removed proteins and lipids from $6 \mathrm{~mL}$ LB medium by two-phase extraction. The aqueous layer containing nucleic acids was obtained by centrifugation at $12,000 \times g$ for $10 \mathrm{~min}$ with phenol:chloroform (1:1 v/v; Sisco Research Laboratories). RNA-free glycogen $(0.2 \mathrm{mg} / \mathrm{mL}$; SD Fine Chemicals, Mumbai, Maharashtra, India), one-tenth volume $3 \mathrm{M}$ sodium acetate (Merck, Mumbai, India), and 2.5 volumes absolute ethanol (Sisco Research Laboratories) were added to the aqueous phase. After incubation of the mixture $\left(-70^{\circ} \mathrm{C}\right.$ for 30 $\mathrm{min})$, it was centrifuged at $12,000 \times g$ for 10 $\mathrm{min}$. The precipitate was washed twice with $0.5 \mathrm{~mL} 70 \%$ (v/v) ethanol, air-dried, dissolved in $60 \mu \mathrm{L}$ nuclease-free water (Fermentas, Glen Burnie, MD, USA), and divided into three parts of $20 \mu \mathrm{L}$ each, which were individually treated with $5 \mu \mathrm{g}$ RNaseA, $0.25 \mathrm{U}$ DNase (Promega Scientific, San Luis Obispo, CA, USA) for $3 \mathrm{~h}$ at $37^{\circ} \mathrm{C}$, and $5 \mu \mathrm{L}$ water, respectively (20). Samples were subjected to electrophoresis in TBE buffer $(0.045 \mathrm{M}$ Tris-borate and 0.001 M EDTA, pH 8.3; Sisco Research Laboratories) at $100 \mathrm{~V}$ on $1.5 \%(\mathrm{w} / \mathrm{v})$ agarose gels (Sisco Research Laboratories) containing ethidium bromide $(0.5 \mu \mathrm{g} / \mathrm{mL}$; Sisco Research Laboratories) (21).

\section{Analysis of sRNA fragments by}

denaturing urea PAGE

Twenty-five micrograms sRNA fractions obtained from IN-LB and HI-LB were analyzed on $15 \%$ denaturing PAGE containing $6 \mathrm{M}$ urea. A mixture of single-stranded (ss) DNA (oligomers of 20, 23, 40, 56 nucleotides; MicroSynth, Lindau, Germany) and ssRNA (50-1000 nucleotides; New England Biolabs, Hitchin, OTY, UK) were used as molecular size markers to deduce the size of sRNA fractions. Electrophoresis was carried out at $25 \mathrm{~mA}$ with $0.5 \times \mathrm{TBE}$ as the running gel buffer and stained with $0.5 \times \mathrm{TBE}$ containing ethidium bromide $(0.5 \mu \mathrm{g} / \mathrm{mL})(21)$.
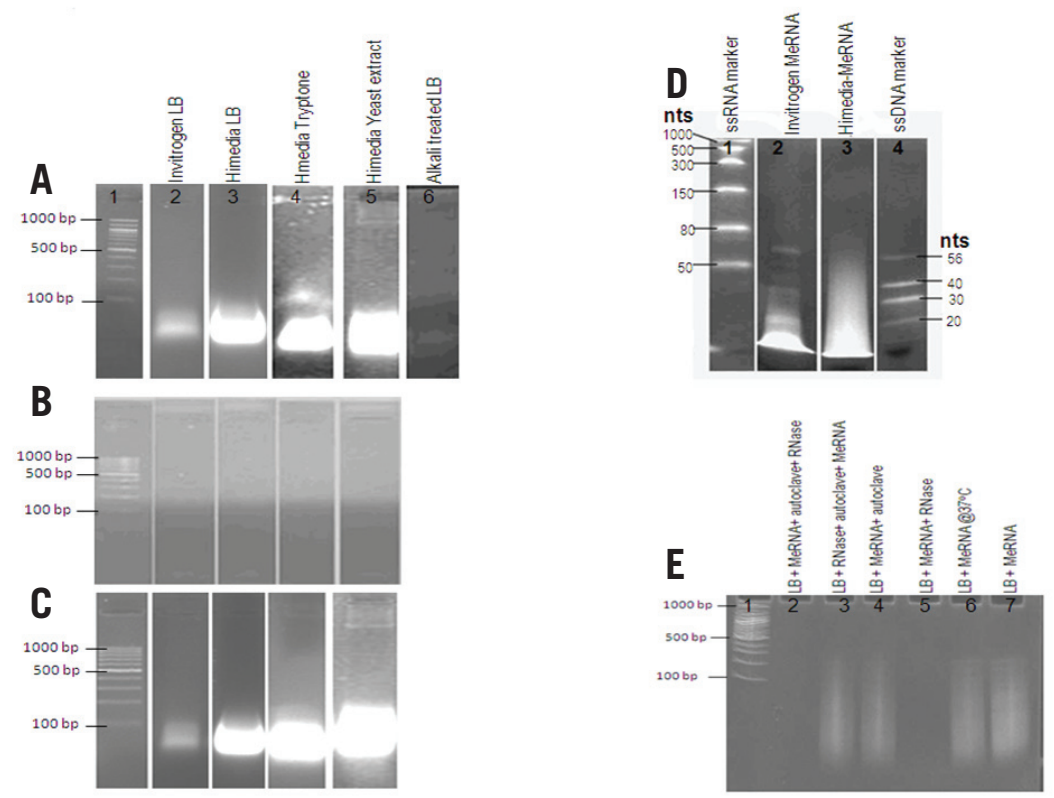

Figure 1. Presence of sRNA in LB and its components. (A) Presence of SRNA in HI-LB, IN-LB and their components (B) confirmation for the nucleic acids to be RNA as they are hydrolyzed by RNase. (C) DNase treatment did not affect the nucleic acid bands. (D) Denaturing PAGE analysis ascertained the sizes of small RNA to be $<100 \mathrm{bp}$. (E) meRNA was seen to be stable even after incubation at $37^{\circ} \mathrm{C}$ and autoclaving, but RNase activity was inactivated after sterilization of LB. nts, nucleotides. DNA size markers (panels A, B, C, and E) $=$ Generuler 100 bp DNA Ladder (Fermentas Inc., Glen Burnie, MD, USA). RNA size marker (panel D) = Low Range ssRNA Ladder (New England Biolabs, Hitchin, OTY, UK).

Stability analysis of sRNAs present in the LB medium

This experiment was performed using the following preparations: (i) $1 \mathrm{~mL}$ RDLB was mixed with sRNAs isolated from $1 \mathrm{~mL}$ HI-LB medium, prior to electrophoresis; (ii) $1 \mathrm{mLRDLB}$ was mixed with sRNAs isolated from $1 \mathrm{~mL} \mathrm{HI-LB}$ medium and incubated at $37^{\circ} \mathrm{C}$ for $1.5 \mathrm{~h}$; (iii) $1 \mathrm{~mL}$ RDLB was mixed with sRNAs isolated from $1 \mathrm{~mL} \mathrm{HI-LB}$ and treated with $0.5 \mu \mathrm{g} / \mathrm{mL}$ RNaseA and incubated at $37^{\circ} \mathrm{C}$ for $1.5 \mathrm{~h}$; (iv) $1 \mathrm{~mL}$ RDLB was mixed with sRNAs isolated from $1 \mathrm{~mL}$ HI-LB medium, incubated at $37^{\circ} \mathrm{C}$ for $1.5 \mathrm{~h}$, and autoclaved; $(v) 1 \mathrm{~mL}$ RDLB was treated with $0.5 \mu \mathrm{g} / \mathrm{mL}$ RNaseA, incubated for 1.5 $h$, and autoclaved; this preparation was again incubated with sRNAs (from $1 \mathrm{~mL} \mathrm{HI-LB}$ ) for $1.5 \mathrm{~h}$ at $37^{\circ} \mathrm{C}$; (vi) $1 \mathrm{mLRDLB}$ was mixed with sRNAs isolated from $1 \mathrm{~mL}$ HI-LB, incubated at $37^{\circ} \mathrm{C}$ for $1.5 \mathrm{~h}$, autoclaved, and incubated with $0.5 \mu \mathrm{g} / \mathrm{mL}$ RNaseA at $37^{\circ} \mathrm{C}$ for $1.5 \mathrm{~h}$. About $50 \mu \mathrm{L}$ each preparation were analyzed on denaturating urea-PAGE.

Preparation of reconstituted LB media

Reconstitution experiments were performed to examine whether the sRNAs arising from LB medium contribute to changes in protein profiles of bacteria. In order to conduct this experiment, nucleic acids (containing sRNA) were obtained aseptically from $3 \mathrm{~mL}$ LB medium (from both HI-LB and IN-LB) by ethanol precipitation, as described earlier. Ethanol precipitate thus obtained from 3 $\mathrm{mL} H \mathrm{HI}-\mathrm{LB}$ was added to the same volume of IN-RDLB and vice versa. Reconstituted LB media were used to culture the bacteria, and their proteins were analyzed.

Preparation of whole-cell lysates and protein profile analysis by SDS-PAGE The five strains, E. coli DH5 $\alpha$ and BL21 (DE3), S. typhimurium, S. flexneri, and EPEC, were cultured by incubating overnight at $37^{\circ} \mathrm{C}, 180 \mathrm{rpm}$. Approximately $3 \mathrm{~mL}$ RDLB and reconstituted RDLB prepared from HI-LB and IN-LB were seeded with $5 \%$ of the above cultures, respectively. The volumes corresponding to $0.7 \mathrm{OD}$ at $595 \mathrm{~nm}$ were centrifuged in $2-\mathrm{mL}$ microcentrifuge tubes at $4500 \times g$ for $5 \mathrm{~min}$. The obtained cell pellets were washed twice with $0.5 \mathrm{~mL}$ TE buffer (20 mM Tris-HCl, 10 mM EDTA, pH 7.4), suspended in $25 \mu \mathrm{L} 4 \times \mathrm{SSB}$ ( $40 \%$ glycerol, $8 \%$ v/v $\beta$-mercaptoethanol, 32\% w/v SDS, 0.02\% Bromophenol blue), and heated in a dry bath for $10 \mathrm{~min}$. Resulting suspensions were centrifuged at $12,000 \times g$ for $10 \mathrm{~min}$, and the supernatants were analyzed on SDS-PAGE (12\% polyacrylamide; $15 \times 13 \mathrm{~cm}$ ) using Tricine as tank buffer instead of Tris-glycine $(25 \mathrm{mM}$ Tris-HCl, $200 \mathrm{mM}$ Tricine, $0.1 \% \mathrm{w} / \mathrm{v}$ SDS, $\mathrm{pH}$ 8.3). Electrophoresis was performed at 40 $\mathrm{mA}$, and the resolved proteins were stained using Coomassie Brilliant Blue (CBB) R-250 (Sisco Research Laboratories).

\section{Results and discussion}

Based on studies demonstrating protein expression regulation by $s$ RAs, along with their pervasive roles in cellular homeostasis $(4,7,8,17,19,22)$, we speculated that small 
3D CELL

CULTURE

alvetex scaffold

Alvetex ${ }^{\circledR}$ Scaffold enables genuine 3D cell culture to be achieved simply and routinely.

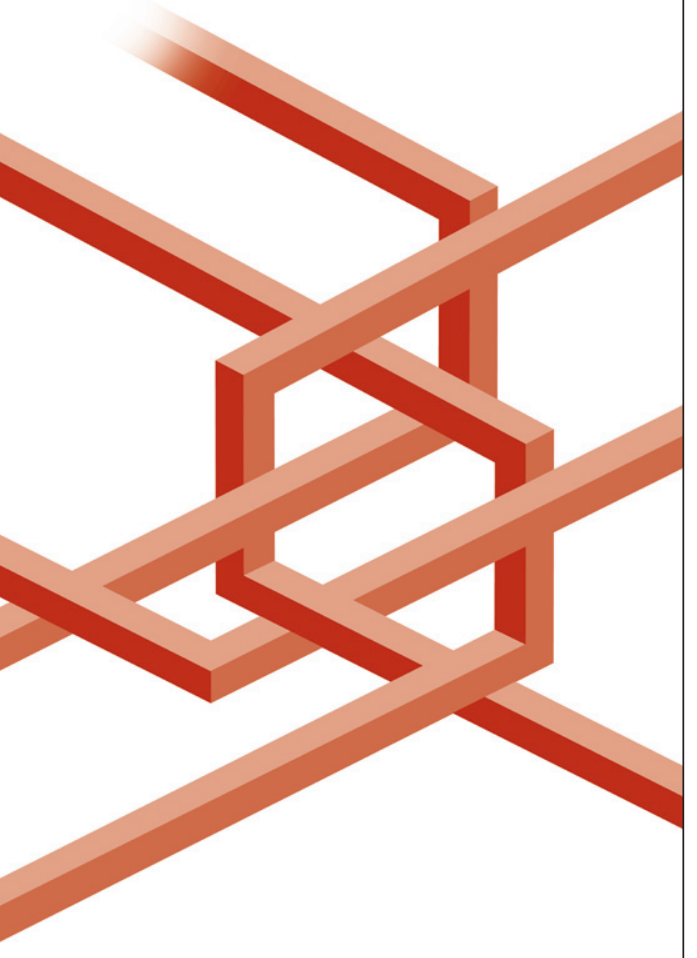

Alvetex ${ }^{\circledR}$ Scaffold is designed and developed with the specific needs of cell biologists in mind.

To find out more and request your FREE evaluation visit:

www.reinnervate.com

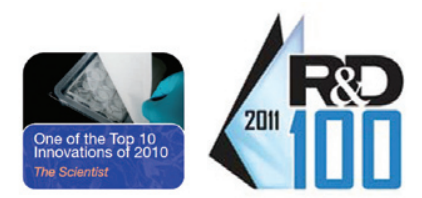

fragments of RNA in LB medium could cause variation in either growth or protein expression profiles. Hence, we examined the growth and protein profiles for five different bacterial species grown in LB obtained from two different manufacturers, as well as in LB media that had been RNA-depleted.

\section{Heat-stable sRNAs in LB media}

Agarose gel electrophoresis of nucleic acid extracts prepared from either HI-LB or IN-LB revealed the presence of small, heat stable nucleic acids less than $100 \mathrm{bp}$ (Figure 1A). Corroborating our initial gel analysis, spectrophotometric analysis $\left(\mathrm{A}_{260} / \mathrm{A}_{280}\right)$ revealed the presence of about 30 and $100 \mu \mathrm{g}$ nucleic acids/ $\mathrm{mL}$ in IN-LB and HI-LB, respectively (Figure $1 \mathrm{~A}$, lanes 2 and 3). These nucleic acid species were subsequently identified as RNA by virtue of their lability (Figure 1A, lane 6) to alkali and digestibility by RNaseA (Figure 1B), but not by DNase (Figure 1C). The ingredients of HI-LB (tryptone and yeast extract) also exhibited a prominent band below 100 bp (Figure 1A, lanes 4 and 5). However, denaturing PAGE analysis revealed the sizes of sRNA at $\sim 10-80$ nucleotides in the form of nondistinct bands in HI-LB and distinct bands in IN-LB (Figure 1D). Since sRNAs were observed even after autoclaving (Figure 1E, lanes 3 and 4) and following various manipulations and incubations at $37^{\circ} \mathrm{C}$ (Figure 1E, lane 6), we report that these sRNA fractions are quite stable.

\section{sRNA in LB medium alters protein} profiles of bacteria

To test our hypothesis that these sRNA fragments affect cellular protein profiles, RNA fragments had to be specifically removed from the medium. Accordingly, LB was treated with RNase to digest the RNA prior to autoclaving. Subsequent autoclaving inactivated the RNaseA enzyme completely, as evident from the inability of the medium to hydrolyze sRNA isolated from LB (Figure $1 \mathrm{E})$. This ruled out the possibility of any effect due to the presence of active RNase in the medium.

Although there are two convenient methods to eliminate RNA from a medium, namely alkali-treatment and RNasetreatment, we found bacterial growth rates were significantly reduced in alkali-treated LB compared with autoclaved, RNase-treated LB (RDLB; data not shown) (Figure 1E). To test the effect of sRNA in the medium on the regulation of bacterial protein expression, we utilized the common laboratory strains $E$. coli DH5 $\alpha$ and BL21 (DE3) as well as a pathogenic $E$. coli strain, EPEC, and two other common enteropathogens, $S$. typhimurium, and $S$. flexneri. SDS-PAGE analysis of the cell lysates of the above mentioned five bacterial strains cultured in three different media (LB, RDLB, and reconstituted RDLB either with
HI-sRNA or IN-sRNA), showed significant changes in the subcellular protein profiles in response to the interference of sRNA in the LB medium (Figure 2).

Most strikingly, a prominent $85-\mathrm{kDa}$ protein was seen in the profiles of the avirulent E. coli strain $D H 5 \alpha$ (Figure $2 \mathrm{~A}$ ) and two virulent strains, $S$. typhimurium (Figure 2D) and EPEC (Figure 2E), when cultured in HI-LB, HI-RDLB supplemented with HI-sRNA, and IN-RDLB supplemented with HI-sRNA, but not in sRNA-depleted HI-LB or IN-LB and the same supplemented with IN-sRNA. However, S. flexneri (Figure 2C) and E. coli $\mathrm{DH} 5 \alpha$ (Figure $2 \mathrm{~A}$ ) revealed a prominent protein of $<14 \mathrm{kDa}$ in the same conditions. In case of E. coli BL21 (DE3) (Figure 2B), a prominent 65-kDa protein was seen in response to IN-sRNA when the strain was cultured in IN-LB, IN-RDLB supplemented with, and HI-RDLB supplemented with IN-sRNA. Apart from the minor differences, to our surprise, we noticed significant differences between the protein profiles of the bacteria cultured in HI-LB and IN-LB, which were marked as dots in all the gels (Figure 2). It is noteworthy that differences in protein profiles when the same bacteria (tested in the case of the five strains) was grown in LB prepared from $\mathrm{HI}$ and IN components were eliminated when the sRNA in the medium was depleted and then reappeared when HI-sRNA was added back (indicated in red arrows).

We speculate that a modest carryover of sRNAs in LB could act posttranscriptionally through complementary pairing with target mRNAs to regulate protein expression, as it is increasingly evident from the recent studies on the effect of sRNA on posttranscriptional regulation of protein translation. This turned out to be the case for the variations in wholecell protein profiles of five different bacteria grown in two different LB sources, which were reduced drastically upon sRNA removal using RNase and recapitulated upon reconstitution of both sRNA-depleted HI-LB and IN-LB.

In order to minimize any experimental artifacts associated with cell processing, wholecell lysates were prepared by boiling the cells in SDS-sample buffer and were analyzed electrophoretically. Although it is possible that such a heterogeneous sRNA pool could affect growth, we did not observe any significant growth changes for the five different bacterial species tested or in the two LB preparations used. It has been reported that antisense sRNAs can positively regulate protein expression (promoting ribosome binding) or negatively regulate protein expression (destabilizing or preventing translation by binding to the mRNA of target protein) without altering growth profiles, which is confirmed by this study, in agreement with similar reports $(4,7,17,22)$. The well-established regulatory 


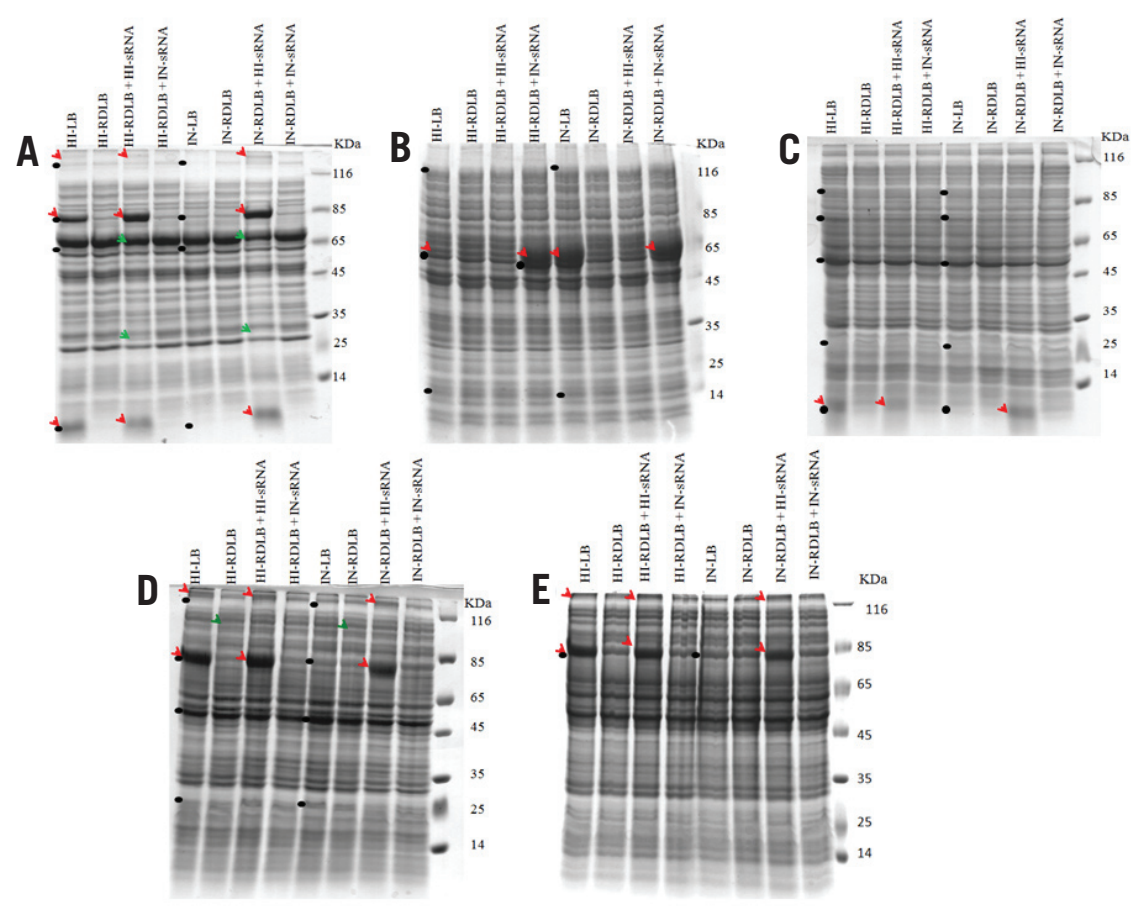

Figure 2. Effect of SRNA in LB medium on the protein profiles of five different bacteria. The protein profiles of subcellular proteins on SDS-PAGE for five different bacteria are shown. Three types of differences in the protein profiles are indicated: (i) prominent differences are marked by red arrows; (ii) differences due to brands of media components (HI-LB and IN-LB) are marked by black dots; and (iii) minor variations in expression level are marked by green arrows. Duplicates (representing biological replicates) of these gels can be seen in Supplementary Figure S1. (A) E. coli DH5 $\alpha$. Subcellular proteins of E. coli DH5 $\alpha$ showed the expression of three protein of $>110 \mathrm{kDa}, 85 \mathrm{kDa}$, and $<14 \mathrm{kDa}$ in the lanes HI-LB, HI-RDLB $+\mathrm{HI}$-sRNA, and IN-RDLB + HI-sRNA. Also, there were minor differences in the expression levels of the $>65 \mathrm{kDa}$ protein and the between 35 and $25 \mathrm{kDa}$ protein. (B) E. coli BL21 (DE3). A prominent protein at $65 \mathrm{kDa}$ was seen only in IN-LB, but not in HI-LB. However, when IN-RDLB and HI-RDLB were supplemented with IN-sRNA, the band could be seen. (C) S. flexneri. A prominent $<14 \mathrm{kDa}$ protein was observed in $\mathrm{HI}-\mathrm{LB}$ but not in IN-LB. It appeared when HI-RDLB and IN-RDLB were supplemented with HI-sRNA. Also, a few minor differences in several other proteins of the bacteria cultured in HI-LB and IN$\mathrm{LB}$ have been indicated. (D) S. typhimurium. Two prominent proteins of $>110 \mathrm{kDa}$ and $<85 \mathrm{kDa}$ in $\mathrm{HI}-$ LB, and in HI-RDLB and IN-RDLB supplemented with Hi-sRNA are indicated. A few other proteins with expression level differences are also indicated. (E) EPEC A5. Similar to E. coli DH5 $\alpha$ and S. typhimurium, a prominent protein of $85 \mathrm{kDa}$ was observed in $\mathrm{HI}$-LB but not in IN-LB. This protein also appeared when $\mathrm{HI}$-RDLB and IN-RDLB was supplemented with HI-sRNA. The prominent $<14 \mathrm{kDa}$ protein seen in $E$. coli $\mathrm{DH} 5 \alpha$ and $S$. flexneri were not seen in EPEC, even though it is a variant of the E. coli species. Protein marker = Unstained Protein Molecular Weight Marker (Fermentas Inc., Hanover, MD, USA).

roles of sRNA in bringing about changes in protein expression and metabolism leading to phenotypic characteristics or variations lead us to speculate that transfer of sRNA between cells or from the environment could be a plausible mechanism for phenotypic adaptation $(22,23)$. Specific reports, including sRNA-based regulation of genes involved in the iron metabolism, expression of outer membrane proteins $(17,24)$, and virulence genes during host-pathogen interactions (25), have been increasingly reported as of late. Although instances of naturally occurring antisense RNA have been known for many years, the role of sRNAs released during RNA biogenesis in protein degradation and expression is a recent discovery (25). The positive and negative effect of sRNAs on protein expression (24-27) was expected from such a highly heterogeneous RNA pool arising out of random fragmentation of cellular RNA during media production. The sizes of the
RNAs contained in LB were quite similar to that of sRNA effectors of 10-200 bp (28-31). Considering the significance of their effect on bacterial metabolism, we have termed these sRNAs "media RNA" (meRNA).

It is obvious that protein changes as a function of sRNA population in a medium will vary according to: $(i)$ the media ingredients, (ii) batch-to-batch variation, or (iii) different manufacturing process. During the course of this study, we observed specific changes in protein profiles only with a certain batch of HI-LB and IN-LB. When media batches were changed, protein profiles were not reproduced. Since reconstitution experiments in this study clearly demonstrate that the sRNA (meRNA) in the LB media are responsible for the protein profile differences found in five different bacteria, our finding certainly argues for using media devoid of meRNA when making comparisons between studies performed at different geographical locations or using differing batches of the medium within the same lab. Although alkali treatment is an inexpensive method to potentially eliminate meRNA, we have found that alkali treatment of defined media or alkali treatment of RNase-treated media results in significant changes in bacterial proteomics (unpublished results). Hence RNase treatment appears to be the best choice, although this may not be a viable option for industrial processes. Preparation processes or manufacturing of complex media ingredients, such as yeast extract and tryptone, should be carefully studied to ensure the absence of meRNA.

Such a heterogeneous population of sRNA fragments is likely to be ubiquitous in any environment (8) due to the decay of prokaryotic and eukaryotic matter and therefore may be expected to alter protein expression patterns of an organism growing in their presence. Hence, the protein profile changes induced by meRNA tempt us to speculate that the presence of sRNA (derived from a variety of biological materials) in a complex habitat or environment (including pathogens growing in hosts) could potentially affect bacterial growth or colonization and play a role in organismal adaptation.

In conclusion, it is apparent that protein profile alterations of bacteria can be caused by small RNA fragments contained in complex media like LB. Apart from cautioning researchers on the need to use meRNA-depleted medium for bacteriology studies, our findings also open the possibility that exogenous RNA fragments in the environment could modulate endogenous bacterial metabolism and subsequent adaptation. The nature and significance of these meRNA-induced changes, as well as their relevance to recombinant protein hyperexpression, are now under investigation.

\section{Acknowledgments}

We acknowledge Dr. Venkat Gopalan, Department of Biochemistry, Ohio State University, USA for his valuable guidance throughout the work. We acknowledge the financial support from University Grants Commission under Departmental Research Support and Centre with Potential for Excellence in Environmental Science Programmes and European Union project, Each Child.

\section{Competing interests}

The authors declare no competing interests.

\section{References}

1. James, G.C. and S. Natalie. 2001. Microbiology: A Laboratory Manual. Benjamin Cummings Publishing, Tempe, AZ.

2. Chen, J.H., J.C. Lin, J.L. Chang, Y.K. Tsai, and L.K. Siu. 2011. Different culture medium formulations induce variant protein expression patterns 
of outer membrane porins in Klebsiellapneumoniae. J. Chemother. 23:9-12.

3. Fuqua, C., M.R. Parsek, and E.P. Greenberg. 2001. Regulation of gene expression by cell-to-cell communication: acyl-homoserine lactone quorum sensing. Annu. Rev. Genet. 35:439-468.

4. Lenz, D.H., K.C. Mok, B.N. Lilley, R.V. Kulkarni, N.S. Wingreen, and B.L. Bassler. 2004. The small RNA chaperone Hfq and multiple small RNAs control quorum sensing in Vibrio harveyi and Vibrio cholerae. Cell 118:69-82.

5. Gisela, S., J.A. Opdyke, and A. Zhang. 2004. Controlling mRNA stability and translation with small, noncoding RNAs. Curr. Opin. Microbiol. 7:140-144.

6. Wassarman, K.M., A. Zhang, and G. Storz. 1999. Small RNAs in Escherichia coli. Trends Microbiol. 7:37-45.

7. Gottesman, S. 2004. The small RNA regulators of Escherichia coli: roles and mechanisms. Annu. Rev. Microbiol. 58:303-328.

8. Mehta, P., S. Goyal, and N.S. Wingreen. 2008. A quantitative comparison of sRNA-based and protein-based gene regulation. Mol. Syst. Biol. 4:221.

9. Venkataraman, S., R.M. Dirks, C.T. Ueda, and N. Pierce. 2010. A selective cell death mediated by small conditional RNAs. Proc. Natl. Acad. Sci. USA 107:16777-16782.

10. Bassler, B. 1999. How bacteria talk to each other: regulation of gene expression by quorum sensing. Curr. Opin. Microbiol. 2:582-587.

11. Ando, T., H. Suzuki, S. Nishimura, T. Tanaka, A. Hiraishi, and Y. Kikuchi. 2006. Characterization of extracellular RNAs produced by the marine photosynthetic bacterium Rhodovulum sulfidophilum. J. Biochem. 139:805-811.

12. Kay, E., C. Reimmann, and D. Hass. 2006. Small RNAs in bacterial cell-cell communication. Microbe 1:63-69.

13. Buckingham, S. 2003. The major world of microRNAs, Horizon Symposia: Understanding the RNAissance. Nature Publishing Group, Nature, 1-3.

14. Paliy, O., S.M. Gargac, Y. Cheng, U.V. Uversky, and A.K. Dunker. 2008. Protein disorder is

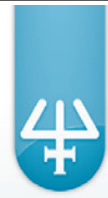

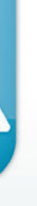
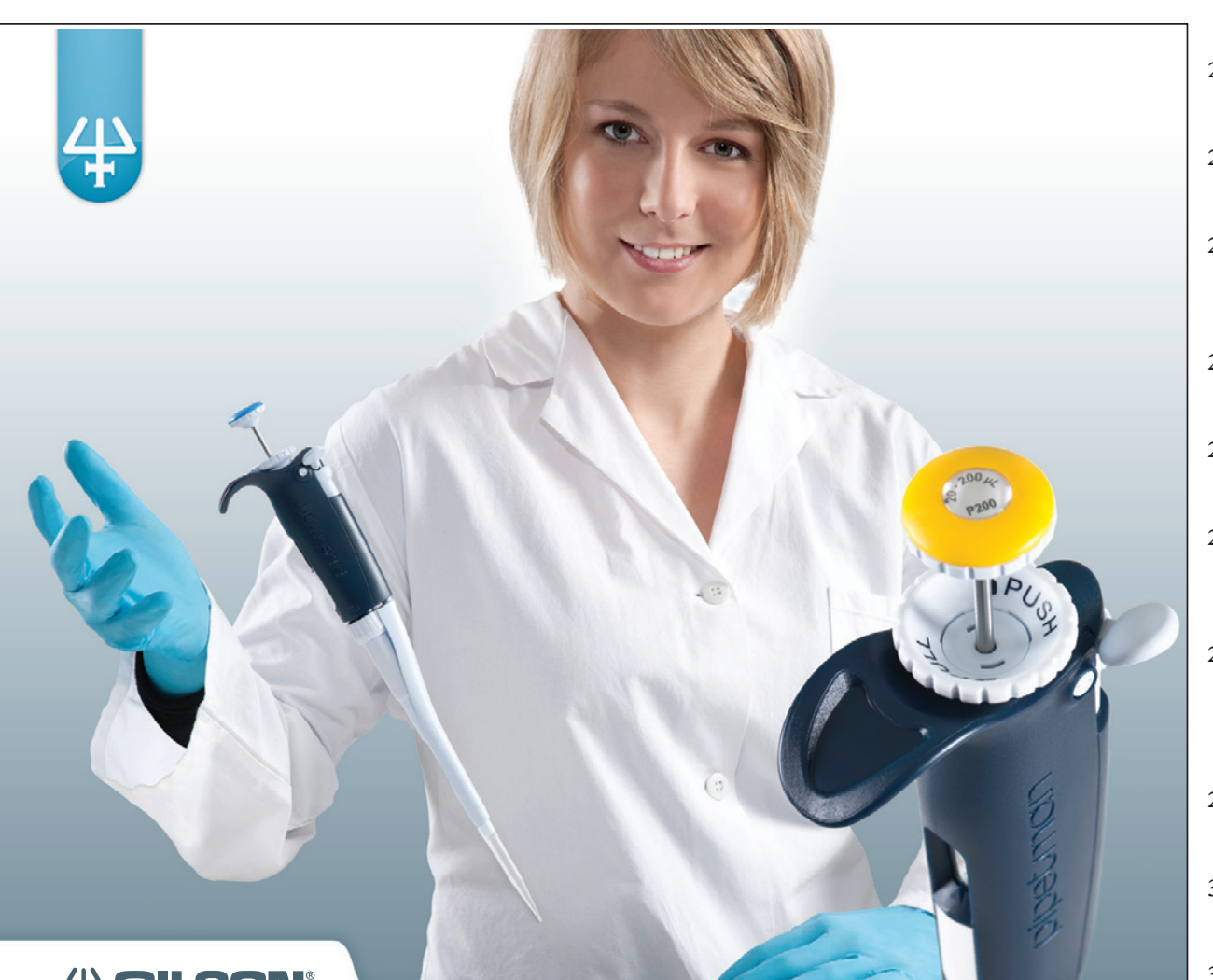
术 GILSON'

\section{Increase Productivity} Without Sacrificing Comfort!

You asked, we delivered. PIPETMAN ${ }^{\circledR} L$ was designed with you in mind pairing legendary PIPETMAN robustness with new features to help you increase productivity and pipette longer without sacrificing comfort.

\footnotetext{
ه Lockable Volume Ensures No Accidental Volume Changes

凶 Lightweight Body for Comfortable Pipetting All Day

$\otimes$ Low Pipetting \& Tip Ejection Forces
}

positively correlated with gene expression in E. coli. J. Proteome Res. 7:2234-2245.

15. Massé, E. and S. Gottesman. 2002. A small RNA regulates the expression of genes involved in iron metabolism in Escherichia coli. Proc. Natl. Acad. Sci. USA 99:4620-4625.

16. Romby, P., F. Vandenesch, and E.G.H. Wagner. 2006. The role of RNAs in the regulation of virulence-gene expression. Curr. Opin. Microbiol. 9:229-236

17. Derrick, H.L., C.M. Kenny, N.L. Brendan, V.K. Rahul, N.S. Wingreen, and B.L. Bassler. 2004. The small RNA chaperone Hfq and multiple small RNAs control quorum sensing in Vibrio harveyi and Vibrio cholerae. Cell 118:69-82.

18. Aranaa, A.T., F. Repoilaa, and P. Cossart. 2007. Small noncoding RNAs controlling pathogenesis. Curr. Opin. Microbiol. 10:182-188.

19. Kawaji, H. and Y. Hayashizaki. 2008. Exploration of small RNAs. PLoS Genet. 4:e22.

20. Kim, V.N. 2005. MicroRNA biogenesis: coordinated cropping and dicing. Nat. Rev. Mol. Cell Biol. 6:376-385.

21.Sambrook, J., E.F. Fritsch, and T. Maniatis. 1989 Molecular Cloning: A Laboratory Manual, 2nd ed. CSH Laboratory Press, Cold Spring Harbor, NY.

22. Gottesman, S. 2003. Regulatory roles for small RNAs in bacteria. Curr. Opin. Microbiol. 6:120124.

23. Takayama, K. and S. Kjelleberg. 2000. The role of RNA stability during bacterial stress responses and starvation. Environ. Microbiol. 2:355-365.

24. Chen, S., A. Zhang, L.B. Blyn, and G. Storz. 2004. $\mathrm{MicC}$, a second small-RNA regulator of Omp protein expression in Escherichia coli. J. Bacteriol. 186:6689-6697.

25. Johansson, J. and P. Cossart. 2003. RNA-mediated control of virulence gene expression in bacterial pathogens. Trends Microbiol. 11:280-285.

26. Hutvagner, G., M.J. Simard, C.C. Mello, and P.D. Zamore. 2004. Sequence specific inhibition of small RNA function. PLoS Biol. 2:e98.

27. Wassarman, K.M., F. Repoila, C. Rosenow, G. Storz, and S. Gottesman. 2001. Identfcation of novel small RNAs using comparative genomics and microarrays. Genes Dev. 15:1637-1651

28. Tjaden, B., S.S. Goodwin, J.A. Opdyke, M. Guillier, D.X. Fu, S. Gottesman, and G. Storz. 2006. Target prediction for small, noncoding RNAs in bacteria. Nucleic Acids Res. 34:27912802.

29. Masse, E., N. Majdalani, and S. Gottesman. 2003. Regulatory roles for small RNAs in bacteria. Curr. Opin. Microbiol. 6:120-124.

30. Storz, G. 2006. Target prediction for small, noncoding RNAs in bacteria. Nucleic Acids Res. 34:2791-2802.

31. Gottesman, S. 2007. Stealth regulation: biological circuits with small RNA switches. Genes Dev. 16:2829-2842.

Received 5 March 2008; accepted 18 January 2012.

Address correspondence to Krishnan Sankaran, Centre for Biotechnology, Anna University, Chennai 600 025, India. e-mail: ksankran@yahoo.com; ksankaran@annauniv.edu

To purchase reprints of this article, contact: biotechniques@fosterprinting.com

\section{pipetman L}

www.PipetmanL.com 